\title{
Rural Women's Workload: Implications for Socio-Economic Development of Baluchistan
}

\author{
Abdul Rasheed \\ Department of Commerce \\ University of Baluchistan \\ Riffat Arshed \\ Department of Economics \\ University of Baluchistan \\ Zeenat Sana Baloch \\ Department of Balochi \\ University of Baluchistan
}

\begin{abstract}
This paper is based on the descriptive sample survey carried out mainly to highlight the issues of heavy workload of rural women within the conceptual framework of triple burden in two districts of Pishin and Mastung and also to explore its research and policy implications in the broader context of province. The key findings include: The burden of reproduction is directly related with domestic workload and was found high in both the districts indicating high fertility with serious health implications. Comparatively speaking, Women in Mastung were found to be involved in greater number in economic activities than Pishin reflecting their high level of deprivation and relatively more cultural freedom. Moreover, they have more control over their income indicating their higher degree of empowerment. Spending priorities reflect that women in Mustang give more importance to education and health. The study concludes heavy workload of rural poor women in terms of domestic chore and reproductive activities provides meaningful insights and suggestions to cope with the problem of exploitative workload.
\end{abstract}

Keywords: Empowerment, Implications, Gender disparity, Triple burden, Workload.

$$
\begin{aligned}
& \text { تخاخص }
\end{aligned}
$$

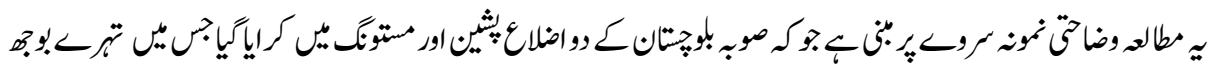

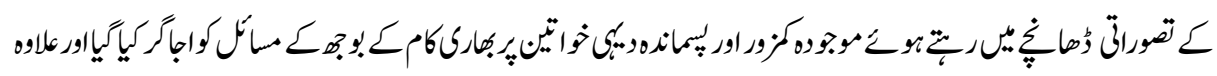

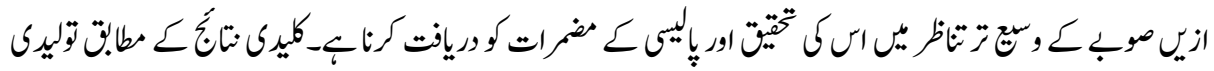

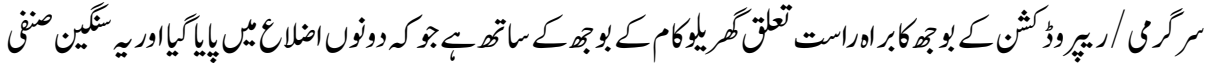

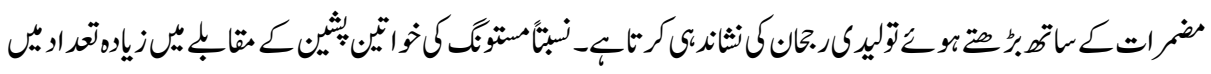

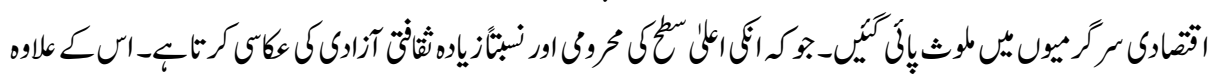




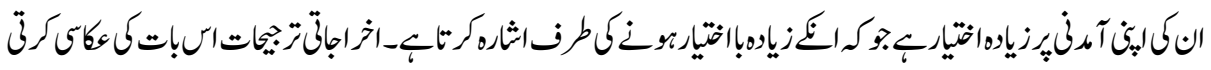

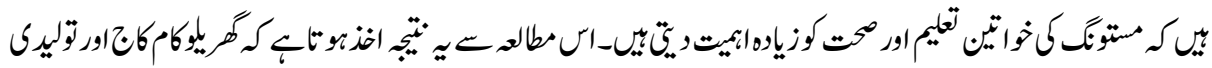

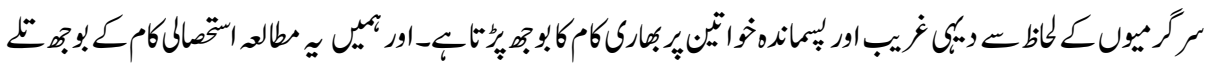

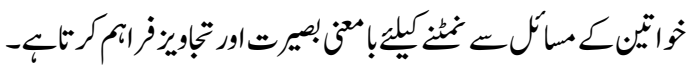

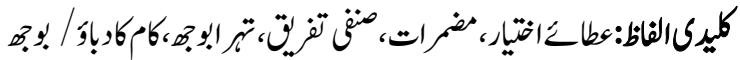

\section{Introduction}

Traditional women work load in the context of rural areas of Baluchistan may be defined in terms of inside and outside activities they normally render and are supposed to be heavier and exploitative. The problem of heavy workload, in case of worst scenario, is further explained as the composition of triple burden (domestic, reproductive and economic) and is compounded by poverty and illiteracy widely prevalent in the most backward rural areas of province (UNICEF, 1995). Another characteristic of women living in worst scenario is that they experience vicious circle of dependencies and vulnerabilities perpetuate their lower and degraded status.

The issue of women's heavy workload and its implications for socio-economic development is highlighted both through national and cross country empirical studies that women who are under heavy traditional work burden are more vulnerable to diseases and poverty (UNICEF, 1993). Heavy traditional household activities have physical and psychological implications (Bennett, 1, 1992). One of the most serious and wide spread occupational health hazards for poor women is the carrying of water, fuel and other heavy loads widely prevalent in the rural areas. Because of their triple burden, as mentioned above, the effects of poverty hit women particularly hard. Similarly empirical evidence on time use show that in most developing countries women work longer than men do; when the invisible work done inside the home is included (World Bank, 2001).

Rural poor women in Baluchistan are even in more critical conditions. The scholarly evidence in this regard, categorically confirms their plights \& vulnerabilities. They have been experiencing challenges and problems with respect to their empowerment (Roath, 2008).Particularly Baloch tribal society being patriarchal, in nature, puts heavy burden in the form of domestic chore and reproductive activities particularly for giving birth to male children (Dashti, 2008). There is also increasing evidence that recent drought and other climate change have increased the volume of workload on rural women of the province. The severe drought spreading over 7 years (1998 -2005) may be considered as one of the worst in the history of province with negative implications for health of women especially on account of water scarcity (Baluchistan Board of Revenue, 2006). 
The irony situation of such work load is that their role is not acknowledged at the family and policy levels in the tribal context of province. Consequently their low socioeconomic status keeps their talents hidden and underutilized, constraining their participation in the formal labor market; and thus, remain vulnerable and dependent.

In view of the above, the need arises to conduct a detailed survey into the causes, pattern and highlight the problems of rural women load work, especially living in the most backward areas of the selected districts.

\section{Objectives of the Study}

The overall purpose of this study is to assess the pattern of women's workload especially living in the rural backward areas of two districts in such a way as to find out its implications for their socio-economic development. The sub objectives are as under:

1. To compare and contrast the workload of rural women living in the study area of two districts.

2. To discover the factors affecting their capacity to work outside the home.

3. To identify the dependencies and vulnerabilities hidden in the traditional workload.

4. To formulate recommendations for durable interventions.

\section{Significance of the Study}

As regards, the nature of study, it is diagnostic in the sense that it was designed to find out the research and policy implications of heavy work load of those rural women who are living in the worst scenario of socio economic environment of province. The study covers important aspects of gender development providing a strong base for other gender related studies, which has not been academically explored so far in the province. The findings and their implications will be helpful in formulating recommendations for appropriate interventions related to women development. Since most of the NGO's are working to reduce women's work load in the rural area therefore the existing empirical work will help them to strategize their interventions especially for those areas that are experiencing the worst scenario of women's conditions.

The paper is organized within the conceptual framework of triple burden of rural woman in terms of home, reproductive and economic responsibilities which are the outcome of vicious circle of deprivations resulting mainly from poverty and illiteracy. Following the introduction, research methodology is described in the second section. The third section discusses domestic workload. The fourth section comparatively describes and analyzes the reproductive and economic activities of women in their respective districts. Finally, the major findings and their policy and research implications will be presented in the fifth section. 
Figure 1: Conceptual Framework

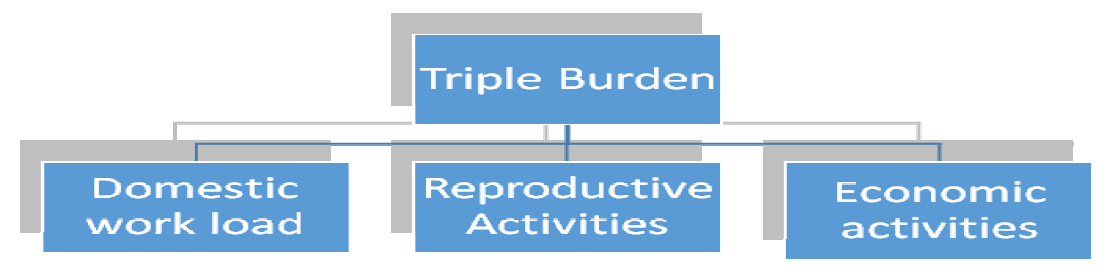

\section{Research Methodology}

The mini survey method was adopted to unfold the burden of women with respect to productive and reproductive work. This method is useful in case of specific topic containing fifteen to thirty questions mostly closed- ended with tiny size of sample (Casley \& Kumar, 1988). The concept of triple workload was further translated and measured in terms of household, reproductive and economic activities. The conceptual framework developed on the bases of literature review, assumes that there is positive relationship between domestic workload and reproductive activities. Moreover, an additional burden was also found in the form of their involvement in the unpaid economic activities. These three burdens, therefore are supposed to reinforce each other in a vicious pattern.

\section{A: Study Area}

A cross-district survey was conducted by the commerce department with the financial assistance of University of Balochistan Quetta. The primary data were collected by using the instruments of questionnaire and observation note book, in the two districts of province, Mustang and Pishin during 2012. The districts were selected for the following reasons. Both the districts, Mastung south of \& Pishin north of Quetta are situated at the equal distance from Quetta (Capital of Baluchistan.) have more or less equal level of socio and economic indicators, and are pre-dominantly rural population with more than (90\%) (District Profiles, 2011) (MICS, 2004). However, culturally they have somewhat different backgrounds having different implications for their work load. For example, Pishin district generally holds stronger patriarchal society; therefore men's control of women is extreme. Ethnically, they are also different. Pishin is exclusively dominated by Pashtoon, whereas the majority of Mastung are Brahui. Three different backward villages of the worst scenario in terms of workload were chosen from each district on the bases of socio-economic conditions such as population, distance from the urban centre, sources of income, level of physical infrastructure etc. In District Pishin, the sample (Thrata, Kazhawala, and Klli Machan) were chosen. While in Mastung the (Khadkocha, Dharanger and Killy Raith) were selected as sample villages. 


\section{B: Sample Size}

As regards the sample size, 50 household from each village was selected by way of simple random sampling. The criteria adopted for the selection of respondents include; a married woman, potentially under triple burden was taken as a sampling unit with the following features (a) age group between 20 to 50 years (b)illiteracy (c) Poverty (d) high fertility and maternal mortality rate and therefore, are supposed to be more vulnerable to diseases and deprivations. Comparable data were collected on the selected factors related to triple work load and income spending by the trained women as in a tribal setup, like Balochistan, they cannot be accessed without female enumerators.

\section{C: Method of Analysis}

The cross -sectional data were analyzed within the conceptual framework of domestic, maternal and productive role by using descriptive statistical tools such as mean and relative percentages for the sake of comparison. Time use data were utilized to determine the volume of inside work load where as economic activities were measured in terms of frequency of involved respondents. The total burden was measured in percentages and presented in figure (1). Moreover, the suggestions of respondents were illustrated with pie charts (2).

\section{Empirical Results and Discussions}

The fact is established by researches that rural women are under heavier workload than their counterpart in the urban area due to deep rooted traditions (Malik, R., 2004). Traditional household activities among poor women are believed to be experiencing the following triple burden in terms of domestic chore, reproductive and unpaid economic role and thus having physical and psychological stresses.

\section{Domestic Workload}

The Survey findings show that in both the sample areas, women are under burden of heavy workload of different household activities, like cooking, dish washing, washing and pressing cloths, cleaning of house, sewing, taking care of children. The structure and time spending were almost the same as is described and shown in table (1).

The survey brings out the fact that cooking is the daily compulsory routine activity taking on average three hour daily. It includes preparation of two meals and breakfast, the entire responsibility of providing food to family lies upon women. It was observed that the majority of women did not take care of nutritional status of food, which reflects not only in their appearance but is also found in the children. Fetching water is another daily activity of 
female family members. On the average mostly half hour daily spent on these activities. It is due to lack of piped water, and aftermath of drought which dried the water inside well of houses. The recent drought especially overburdened the women than men. Washing and pressing clothes is another household responsibility of women. The survey results reveal that both activities take on average two hour daily in both the study areas. Sweeping rooms and grounds is an important daily activity, which is normally performed by housewives and young girls on average; time spending was calculated one hour in both the study areas Women also perform the function of cleanliness of toilets, washrooms, mopping which has an important implication for the hygienic environment of family.

As regards the question whether poor women spend more time on domestic chores, the results (Table 1) confirm the validity of heavy workload in the sample areas; therefore, the need arises to reallocate time to domestic chores in a way that can reduce so called time poverty Hessing, M. (1994). In doing so, they can spare it for both better nurturing of their children and can also enhance their role at the community level.

Table: 1

Comparative profile of domestic workload, as per 12 hours

\begin{tabular}{|l|c|c|}
\hline Activities & Pishin & Mastung \\
\hline Cooking & 02 & 2.5 \\
\hline Breakfast & 0.5 & .5 \\
\hline Lunch & 0.5 & .5 \\
\hline Dinner & 0.5 & .5 \\
\hline Dish washing & 1 & 1 \\
\hline Pressing and washing clothes & 02 & 2 \\
\hline Fetching water & 0.5 & 0.5 \\
\hline Animal care & 0.5 & .5 \\
\hline Cleaning house & 0.5 & 1 \\
\hline Child care & 2 & 1.5 \\
\hline Taking food to field & 0 & .5 \\
\hline Other engagements & 2 & 1 \\
\hline
\end{tabular}

Source sample survey, 2012 (by author)

Note: It is difficult to establish time spending on various activities, as women do not calculate time in hours however, an estimate has been made to get time in hours for performing activities as shown in the above parenthesis.

\section{Reproductive Activities}

The second major burden of traditional women is related with heavy reproductive responsibilities stemming from their maternal role which is supposed to be occurred mainly 
due to early marriages. According to Multiple Indicator Cluster Survey of Baluchistan (2011), on average early (7\%) girls were married before reaching their 15 th birthday and (35\%) before 18th birthday. In addition to early marriages, poor fatherhood, health services both pre and postnatal also put heavy burden on women to bear this specific responsibility. In addition, lack of communities' involvement in safe motherhood program was also found one of the reasons for persistently high mortality rate.

The survey found positive relationship between poor health and reproductive activities in the study area. The burden of reproductive activity in the instant case, are measured in terms of proxy indicators such as high fertility rate, reproductive health related diseases and child care activities. High fertility rate is common in both study areas more than $(6 \%)$ respectively. Child delivery at home through traditional midwife is reported to be $(80 \%)$ in the sample area of area of Pishin and (68\%) in Mastung. High fertility rate has serious implications for their health as it is evident from their experience of pains and stresses as explained in section V. Child bearing and rearing activities increases the manual work among mothers who are already under the vicious circle of poor nutrition and thus vulnerable to diseases especially anemia, and toxemia.

\section{Women Involvement in Economic Activities}

In traditional societies which are characterized by lack of market system, the business of everyday living is usually carried out on gender division of labour (Ivan Illich, 1982). However, it was noted that Baloch and Pashtoon, especially in nomadic life, do not have any segregation of sexes. To examine women's economic role in the sample areas, the majority of respondents were found uninvolved in any outside income generating activity due to limited cultural freedom and therefore, hardly contributed to family welfare (Mohyuddin, Choudhry \& Ambreen, 2012).

To simplify the situation, direct income activities were taken into consideration within the four walls of house or in the neighboring centers. The survey results confirm that the majority of women prefer doing some economic or business activity within the acceptable cultural norms. Out of the total involved respondents in the sample area $(42.65 \%)$ were involved in sewing on non-commercial bases while (35\%) adopt it for income generation. About (4\%) engaged in poultry. Similarly $(1.23 \%)$ were involved in farming and farm related activities as unpaid work. However, findings in Mastung district showed a higher share in income generating activities. 60\% respondents were found in embroidery and handicraft business. As women have significant role in the development of livestock sector in Balochistan (Shafiq, 2008), therefore the study also found them in income generating activities related to livestock and poultry $(6.8 \%, 4.35 \%)$ respectively.

The comparative profile of their respective role in economic activities as is illustrated in (table, 2) clearly reveals the higher percentage of Mastung district. Cross district 
comparison of women involvement shows that the higher percentage of respondents in Mastung were involved in income generating activity both inside and outside of the home, their role in agriculture and livestock is comparatively dominant though the majority of them do it as unpaid family laborers. Moreover, respondents in Mastung district have more economic mobility for the reasons of relatively less rigid environment and higher poverty level.

While analyzing the causes of poor involvement in economic activities, the survey has found the factors such as cultural barriers; dearth of economic opportunities, lack of information and poor economic incentives. However, both positive and negative views on the issue of women workload were found in the study area .Mastung was found less rigid in terms of male attitude towards working of women outside the home. The dominant perception prevailing among male members in Pishin is that women cannot pay any productive role, as they are physically and culturally inferior to male as such their contribution should be confined to the four walls. This finding is in line with the previous regional study conducted in Naseerabad area of province thus, indicating external validity (Rashid and Zainab, 2011).

Table: 2

Comparative profile of economic activities in the selected sample areas by frequency and number in percentage

\begin{tabular}{|l|c|c|c|c|}
\hline & \multicolumn{2}{|c|}{ Pishin } & \multicolumn{2}{c|}{ Mastung } \\
\hline Activities & Frequency & Percentage & Frequency & percentage \\
\hline Farm activities & 10 & $10.2 \%$ & 12 & $11.76 \%$ \\
\hline Cattle & 5.23 & $5.33 \%$ & 4.35 & $4.26 \%$ \\
\hline Vegetables & 20.12 & $21 \%$ & 10 & $10 \%$ \\
\hline Hand Crafts & 10 & $10.2 \%$ & 6.8 & $6.66 \%$ \\
\hline Sewing clothes & 42.65 & $44 \%$ & 60 & $58.82 \%$ \\
\hline Shoe making /others & 10 & $10.2 \%$ & 8.85 & $8.67 \%$ \\
\hline Total & $\mathbf{9 8}$ & $\mathbf{1 0 0} \%$ & $\mathbf{1 0 2}$ & $\mathbf{1 0 0 \%}$ \\
\hline
\end{tabular}

Source: Sample Survey, 2012 (by author)

Comparing the different burdens, the study has found the different level of triple work between two districts as are evident from the following (figure2) showing the sum of total burden. Women in Pishin carries more burden in terms of reproductive activities 55\% for the reasons of high fertility rate due to early marriages. The same region was also found more backward in terms of economic role just $10 \%$ as compared to Mastung. 
Fig 2: level of triple work in Pishin District Pishin
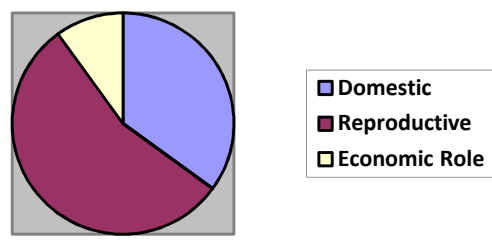

Domestic Reproductive Economic Role $35 \%$ $40 \%$
$25 \%$
Fig 3: level of triple work in Mastung District Mastung

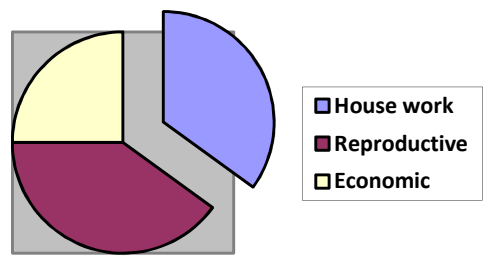

House work Reproductive Economic $35 \%$

$55 \%$ $10 \%$

\section{Pattern of Income Spending}

Pattern of income spending is an important indicator of judging women's autonomy and control over family resources therefore, it has important implications for workload. Women, who are generating income through economic activities, are believed to be less vulnerable to the stresses of heavy domestic workload. According to the survey findings, the majority of respondent were found doing economic activities without receiving any economic reward. However, a few number of women $9 \%$ were involved in income generating activities in Pishin district spend their earned income on children schooling. $29 \%$ allocate on food and $20 \%$ on clothing, whereas $7.8 \%$ on day to day expenses like children pocket money and $4 \%$ income go to the family medicine. The pattern results therefore, suggest more autonomy for women in this regard. On the other hand, in Mastung, 53\% respondents spend on education, which is $10 \%$ higher than Pishin. Respondents $17.7 \%$ spend on food $12 \%$ on cloths, $7.3 \%$ spend on daily expenses and $7 \%$ consume on medicine. Comparing the pattern of expenditure between two districts, one can say women in Mastung have more control over their income indicating that they are less dependent on their male partners. Their priorities also reflect that they give more importance to education whereas women in Pishin give less priority to it.

\section{The Impact of Heavy Workload on Health}

One of the objectives of survey was to assess the impact of traditional workload on health. The main purpose of asking health related questions was to assess the level of consciousness of women about the consequences of workload on their health keeping in view the prevalent cultural values. Since there is positive link between heavy work load and ill health especially maternal and neonatal health, therefore, it was assumed that if they care for their health during housework or economic activities, they are unlikely to be vulnerable to diseases. Similarly in case they are experiencing diseases, but persist in doing work are likely to prolong their diseases and thus will remain under the burdens of 
dependencies and vulnerabilities. The studies also confirm the complex interaction of women workload and their health due to socio economic conditions in the province (Balochistan conservation strategy, 2005).

As per survey results, in Pishin the majority of respondents (33\%) are not paying proper attention to their health during housework activities. Similarly, 31\% respondents pay attention to their health doing housework. The reasons they mentioned were that there is no other option but to continue house job as there is no work load sharer. In fact, such women are more vulnerable to ill health and exploitation that cannot give care to their health during housework activities. $31.30 \%$ respondents stated that they pay due attentions to their health. In case of illness, they avoid doing any housework activities. To some extent, $23 \%$ respondents care for their health.

As compared to Pishin, Mastung presents better situation with respect to health consciousness, as the sample women were found more conscious about their health. This is largely because of customary role of birthing specialists' midwives locally known as (Baluk) who socially mobilize them practically give home grown drugs and back rub (Dashti, 2008). The Majority of respondents (60\%) in the Mustang study area said that they cure and maintain their health with traditional herbs.

Moreover some traditional beliefs were found in the both sample areas about the burden of work load and its negative outcomes on health. The dominant views especially among aged women contradict the idea that physical work leads to negative outcome rather it is sort of exercise keeping women healthier. So much so they also deny the negative effects of more children. What is needed is to the change traditional beliefs regarding workload and health through education.

\section{Suggestions for Reducing Workload}

Reducing workload is a key indicator of women development. There is a consensus among the development practitioners that the projects with positive impacts on work load should be considered successful and sustainable. Realizing its importance, the project impact studies give considerable importance to this issue in their assessment.

Using the open ended questions, the views of respondents were sought as how to reduce their workload. The survey found most of the suggestions pertinent with the social sector development. With minor differences, the availability of drinking water was found on top of the list simply because in most cases they fetch water from distant sources, followed by social services such as health particularly TBA services, education, shortage of electricity, poor transportation as is illustrated in the following figure: 


\section{Figure: 4 and 5 Respondents Suggestions for Reducing Workload Mastung \\ Pishin}
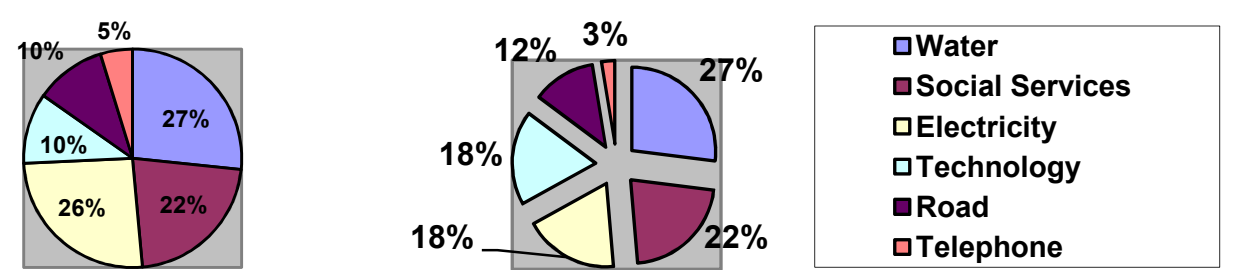

\section{Findings and Recommendations}

One of the objectives of this study was to bring out the policy and research implications of rural women workload therefore; the observations and suggestions based on the findings are presented as under.

1. The overall paradigm shift is needed in the government policies and programs, as the current programs do not address the needs of women More Specific projects with the clear cut identification of women as beneficiaries and as an agent have to be launched .In this regard, more institutionalized efforts are needed.

2. Women workload with respect to child bearing and rearing in terms of time consumption is very low in both the districts due to high fertility rate. Therefore, the need arises to improve the access of respondents to family planning services and get the existing reproductive health canters more functional.

3. Women's workload regarding fetching and managing water is increasing day by day mainly due to two reasons persistent drought and loads shedding .More efforts are needed to improve the situation.

4. During the survey, a strong link was found between education and vulnerability of women to poverty and diseases. Since the girls' literacy rate is negligible, more strenuous efforts are needed to improve the female enrollment ratio.

5. Keeping in view the socio-cultural rigidities of the sample areas, an approach preferably at grass root level must be adopted to enhance the "inside" role of women in the fields of motherhood and family care.

6. During the survey, it was observed that Women's awareness about gender development activities is very poor in spite of the fact, that NGOs like BRSP, SPO, and international organizations such as UNDP and UNICEF were found working in such activities in both the districts. One of the reasons noted was the perception of respondents about bad reputation of NGOs. What is needed is to coordinate the efforts of development agencies government health department to increase the awareness level of women through local media. We also need to change certain traditional beliefs and perceptions regarding reproductive health causing heavy workload with the help of education and dissemination of knowledge. 
7. Women's involvement in direct income generating activities was found very poor in both the sample areas due to cultural rigidities despite the fact that the majority of respondents were willing to work at home. Stimulating home based economic activities like embroidery, gardening livestock, poultry and developing small scale cottage industries at community level can serve the purpose.

8. Another important policy implication arises from the perception of women that they cannot bring about any change unless male attitude is favorably changed especially in Pishin. Gender development interventions through social mobilization of male can address the issue of the burden of women.

\section{Conclusions}

The study has made an effort to bring out the issues of traditional work load of rural poor women on the surface within the conceptual framework of triple burden. While evaluating the main findings, the study has found that women are suffering from the exploitative domestic work load. As a result, social exclusion and vulnerability perpetuate the poor status of women in a vicious way. The proportion of reproductive burden was found higher than other two burdens. However, the role of women in community management was found weaker due to cultural and social rigidities especially in Pishin district. Another finding may be drawn from the pattern of income spending that women involved in economic activity has contributed to family welfare by way of spending on education, nutrition and other child care activities suggesting positive intergenerational effects. The recommendations and findings of the study need to be incorporated into any local gender development strategy. Moreover deeper micro level studies at village level are needed to be carried out to capture the women's work inside and outside the houses within the above nexus of triple burden.

\section{References}

Abdul Rashid \& Zainab Bibi, (Summer 2011). Women's Socio economic Empowerment through Participatory Approach. A Critical Assessment, Pakistan Economic and Social Review, vol. 49:1, pp.133-148.

Balochistan Conservation Strategy (2005). https://portals.iucn.org/library/sites/library/ files/documents/WCS-PK-034.pdf

Casley, Dennis J. \& Krishna, Kumar (1988). The Collection, Analysis and Use of Monitoring and Evaluation Data. Baltimore: The Johns Hopkins University Press.

Government of Balochistan, (planning \& development department) Multiple Indicators Cluster Survey, (2011). 
Government of Baluchistan (Board of Revenue,) June (2006).Contingency Plan for Drought Affected Districts of Baluchistan, p.12.

Government of Balochistan (Planning and Development), (2004), (2011). District Profiles, Pishin, and Mastung. (MICS survey).

Hessing, M. (1994). More than Clock Work: Women's Time Management in their Combined Workloads http:/www.jstor.org/view/073114/ap050048/05aooo8o/0 International labor organization (1998).

IUCN. (2000). Baluchistan Conservation Strategy, Chapters 12 \& 14, PP. 183, 203, 46.

Illich, I. (1982). Gender. New York: Pantheon.

Malik, R. (2004). Study of the Workload of the Urban Employed Woman and its Impact on her Performance and Family Life in Quetta City. Baluchistan Study Center, University of Baluchistan: Quetta-Pakistan, pp.83-84.

Mohyuddin, Choudhry \& Ambreen (2012). Economic Empowerment of Women in the Rural Areas of Balochistan, Pakistan Journal of Women's Studies: Alam-eNiswan, vol.19:2, pp.239-257, ISSN: 1024-1256.

Muhammad Sana Baloch. (2012). Status of Women in the Baloch Society, Annual Research Journal Department of Balochi (Hankeen) pp1-17, University of Balochistan, Quetta.

Naseer, Dashti (2008). The Culture Context of Health: A Baloch Perspective. Baloch Academy, Quetta, pp.137-138.

Niamir-Fuller, M. (1994). Livestock and Women's Livelihoods: A Review of the RecentEvidencehttp://www.unep.org/experts/Default.asp?Page=profiles\&ExpertI $\mathrm{D}=504 \&$ ShowList $=$ no

Roath, Peterson (2008). Women Empowerment in Challenging Environment, A Case Study from Baluchistan, Development in Practice, vol.18:3, pp.333-344.

Shafiq, M. (2008). Analysis of the Role of Women in Livestock of Balochistan. Pakistan. J. Agri. Soc.Sci., 4:18-22.

UNICEF. (United Nations Children Fund) \& Government of Baluchistan (1995). An Analysis of the Situation of Women and Children in Baluchistan, Quetta: pp.45-46. 
UNICEF. (1993), Girls and women Development priority, pp.42-51.

World Bank Development Report. (2000-2001). Attacking Poverty, Washington DC, p. 218 .

Dr. Abdul Rasheed is an Assistant Professor in the Department of Commerce, University of Baluchistan, Quetta.

Mrs. Riffat Arshed is Chairperson in the Department of Economics, University of Baluchistan, Quetta.

Dr. Zeenat Sana Baloch is Professor in the Department of Balochi, University of Baluchistan. 